\title{
Autonomous Robotic Following Using Vision Based Techniques
}

\author{
Robert T. Kania \& Michael Del Rose \\ US ARMY RDECOM -TARDEC \\ Warren, MI 48397-5000
}

\begin{abstract}
The Intelligent Systems And Autonomous Controls (ISAAC) robot is an experimental autonomous research platform being developed to advance current dismount following applications. Specifically, vision based following using pedestrian detection. The current standard in mule applications is the following of GPS waypoints. ISAAC is designed to follow a specific person using solely vision based techniques.

The core of the vision based algorithms used in this application is based on years of research from a collaboration of government and university partners. Stereo vision techniques determine a person, identify them as the leader, and map a path for autonomous following.
\end{abstract}

\begin{abstract}
Ahead Of The Pack
In order to keep with the vision of a more agile army, tomorrow's soldier needs to be as unburdened and mobile as possible. One way to help achieve this goal is to alleviate the individual soldier of non-combat essential gear. By allowing the soldier to leave this gear on some sort of transport, the soldier can march "ahead of the pack" and increase their individual combat effectiveness.

An integral part of this objective, and the future force itself, is the FCS MULE (The Multifunction Utility/Logistics Equipment Vehicle). The MULE is intended to be an unmanned platform capable of providing transport for equipment and supplies in support of dismounted infantry. Anything, that is essential to the mission, but not to the individual soldier, can be placed on the MULE. A similar varient (ARV-Assault (Light) will be capable of carrying armaments to neutralize enemy dismounted infantry as well as suppress fortified positions at a tactical assault range. Other possible capabilities for growth to both the MULE and ARV-A(L) include acting as a battery charging station for future Force Warrior (OFW) personal electronics and other SUGVs, water generation and purifications systems, and advanced sensor suits to aid the soldiers' vision and detect possible threats that unaided would go unnoticed (e.g. chemical or biological threats.)
\end{abstract}

"UNCLASSIFIED" 


\section{Report Documentation Page}

Public reporting burden for the collection of information is estimated to average 1 hour per response, including the time for reviewing instructions, searching existing data sources, gathering and maintaining the data needed, and completing and reviewing the collection of information. Send comments regarding this burden estimate or any other aspect of this collection of information,

including suggestions for reducing this burden, to Washington Headquarters Services, Directorate for Information Operations and Reports, 1215 Jefferson Davis Highway, Suite 1204, Arlington VA 22202-4302. Respondents should be aware that notwithstanding any other provision of law, no person shall be subject to a penalty for failing to comply with a collection of information if it does not display a currently valid OMB control number.

\begin{tabular}{|c|c|}
\hline $\begin{array}{l}\text { 1. REPORT DATE } \\
\mathbf{0 3} \text { FEB } 2005\end{array}$ & $\begin{array}{l}\text { 3. DATES COVERED } \\
\text { - }\end{array}$ \\
\hline \multirow{3}{*}{$\begin{array}{l}\text { A. TITLE AND SUBTITLE } \\
\text { TECHONOMOUS ROBOTIC FOLLOWING USING VISION BASED } \\
\text { TEHIQUES }\end{array}$} & 5a. CONTRACT NUMBER \\
\hline & 5b. GRANT NUMBER \\
\hline & 5c. PROGRAM ELEMENT NUMBER \\
\hline \multirow{3}{*}{$\begin{array}{l}\text { 6. AUTHOR(S) } \\
\text { ROBERT KANIA; MICHAEL DEL ROSE }\end{array}$} & 5d. PROJECT NUMBER \\
\hline & 5e. TASK NUMBER \\
\hline & 5f. WORK UNIT NUMBER \\
\hline $\begin{array}{l}\text { 7. PERFORMING ORGANIZATION NAME(S) AND ADDRESS(ES) } \\
\text { US ARMY TANK-AUTOMOTIVE AND ARMAMENTS } \\
\text { COMMAND,6501 EAST } 11 \text { MILE RD,WARREN,MI,48397-5000 }\end{array}$ & $\begin{array}{l}\text { 8. PERFORMING ORGANIZATION } \\
\text { REPORT NUMBER } \\
\mathbf{1 4 7 4 9}\end{array}$ \\
\hline \multirow[t]{2}{*}{ 9. SPONSORING/MONITORING AGENCY NAME(S) AND ADDRESS(ES) } & 10. SPONSOR/MONITOR'S ACRONYM(S) \\
\hline & $\begin{array}{l}\text { 11. SPONSOR/MONITOR'S REPORT } \\
\text { NUMBER(S) }\end{array}$ \\
\hline
\end{tabular}

12. DISTRIBUTION/AVAILABILITY STATEMENT

Approved for public release; distribution unlimited

13. SUPPLEMENTARY NOTES

14. ABSTRACT

The Intelligent Systems And Autonomous Controls (ISAAC) robot is an experimental autonomous research platform being developed to advance current dismount following applications. Specifically, vision based following using pedestrian detection. The current standard in muel applications is the following of GPS waypoints. ISAAC is designed to follow a specific person using solely vision based techniques. The core of the vision based algorithms used in this application is based on years of research from a collaboration of government and university partners. Stereo vision techniques determine a person, identify them as the leader, and map a path for autonomous following.

15. SUBJECT TERMS

16. SECURITY CLASSIFICATION OF:

a. REPORT

unclassified

\section{b. ABSTRACT} unclassified c. THIS PAGE unclassified
17. LIMITATION OF ABSTRACT

\section{NUMBER OF PAGES}

8 19a. NAME OF RESPONSIBLE PERSON 
The MULE is coming. Multiple variants have been designed and are being tested. Many different methods for the soldier's control of the vehicle are being investigated. One such method is the Leader-Follower approach.

\section{In the Field}

So what is the current state of the art for leaderfollower applications? One of the leaders in this field is the RF ATD (Robotic Follower Advanced Technology Demonstration) program managed at the U. S. Army TARDEC (Tank-automotive and Armaments Research Development and Engineering Center). Under this program, they recently completed experiments using a MULE class chassis. Building upon results from the GPS based following done at

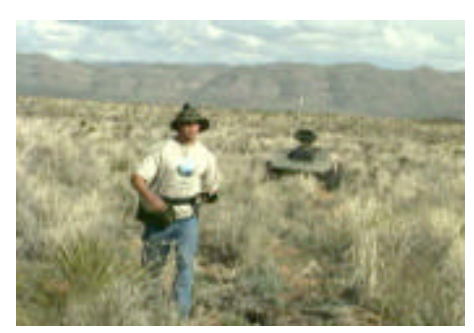
Fort Bliss in March of 2003, they've advanced the technology in the following ways. First, they refined their leader localization accuracy through Human Pedometer technology for dismount navigation to compensate for GPS dropout. Two approaches were developed for this; one by the University of Michigan and the other by Carnegie Mellon University. CMU's approach was tested for accuracy at Fort Indiantown Gap in Dec of 2004 and yielded very promising results. Second, the hardware the leader is required to carry has been reduced and ruggedized with respects to size and power. The current vehicle has been proven to follow a dismounted leader with separation distances as little as $20 \mathrm{~m}$ and time delays up to 6 hours over various terrains from urban to desert.

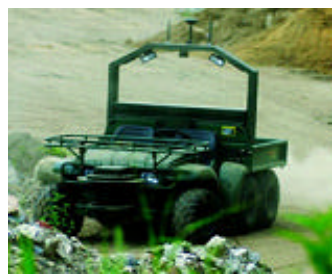

Another up-and-coming leader in this field is the joint effort between iRobot and John Derre. The Military Robotic Gator (R-Gator) project is unique because it will be the first COTS (commercial off the shelf) vehicle for the robotic world. To date, the other vehicles of this size with comparable capability have all been custom-made. The R-Gator is capable of three modes of operation: manual, tele-op, or semi-autonomous. It can be used in dismount applications by being directed to follow soldiers or a set route using GPS waypoints. It could also be used in autonomous convoying, automatically shuttling between rear supply points and forward operating positions by using either manually entered waypoints or those collected dynamically during operations. The first R-Gators are scheduled to roll off the assembly line by mid2005. Full production is planned to begin in 2006.

What do these systems have in common? Both of these platforms are representative of the state-of-the-art of current leader-follower technology being tested by the US ARMY. Both have been tested extensively in the field on proven platforms. And both have a heavy dependence on GPS. A proven technology with proven limitations in the types of environments a dismounted soldier is known to operate. 
In the Footsteps of a Soldier

In a theater of operations a typical war fighter can find themselves in many hostile environments. A large percentage of these environments are not very GPS friendly and many are down right intolerable. Since GPS receivers use signals from satellites they must have a clear view of the sky at all times. In proximity to tall buildings or in dense forest satellite signal may be poor or nonexistent. In order to get a three-dimensional position (latitude, longitude and height) the system requires a lock with a minimum of four satellites; imposing an even greater cover constraint. Also, because GPS is based on RF technology, anything that interferes with radio communications will interfere with GPS more so, because of the lower power and longer range GPS signals must travel. Finally, because most leader-follower applications require more resolution than standard GPS delivers; augmented GPS is required. This is typically thru the use of Differential GPS (DGPS) or Wide Area Augmentation System (WAAS). Both of which require an established infrastructure.

Now let's put this into historical perspective. Since the early twentieth century the United States has been at war six times: World War I, World War II, the Korean War, the Vietnam War, the First Persian Gulf War, and the Iraq War. A large percentage of the conflicts of WWI and WWII could be classified as Urban. Where as both the Korean and Vietnam Wars were fought under the canopy deep in the jungles of both countries. Neither of these environments would be considered ideal for GPS operation. This just leaves the two Gulf Wars. Therefore, two thirds of the United States most recent conflicts were in regions where GPS couldn't be relied upon. And while the open deserts of the Gulf Wars is an ideal environment for GPS usage, the required infrastructure for higher resolution GPS data is somewhat lacking.

\section{Without a Trail}

As was previously mentioned, the current standard in mule applications is the following of GPS waypoints. This requires a considerable amount of hardware on the leader, a dependence on GPS, and an active communications link between the leader and the vehicle. None of these are tactically desirable.

However, a vision based approach could eliminate all these shortcomings. First, a fully developed vision based system would not require the leader to carry any additional hardware to interface with the vehicle. Second, this approach doesn't use GPS and therefore eliminates this dependency. Finally, because there is no additional hardware requirement, there is no need for a communications link to the vehicle. This eliminates the threat that the signal is detected and/or compromised.

These are just a few of the reasons why shifting from a GPS-based to a vision-based model for leader-follower applications would be highly desirable. By reviewing the current GPS-based model's limitations this should have become more apparent.

\section{Meeting the Need}


For the past year and half TARDEC has had two In-house Laboratory Independent Research (ILIR) research projects that have focused on developing technology solutions for this very problem.

The first is the Line-of-sight dismounted leader-follower capability enhancements using pedestrian detection ILIR. The objective of this research is to further the current developments in dismounted leader-follower technologies. Recent work done in the field of leader-follower development has not been focused on dismounted applications. This study focuses on the dismounted soldier while leveraging the technologies developed for the mounted applications - specifically research in the field of pedestrian detection. The goal is to refine pedestrian detection algorithms so that they can be used as the driving force behind dismounted following.

The second, begun about six months ago, is the Pedestrian Detection ILIR. The goal of this research is detect pedestrians in many different scenarios for autonomous and semiautonomous driving. One of the projects under the Pedestrian Detection ILIR is human following. The goal of this project is to use the knowledge of the other pedestrian detection projects in a motion based following capacity.

\section{$\underline{\text { ISAAC }}$}

All robotic research projects need a test bed, a platform vehicle that can be used prove out the technology and keep the developers grounded in reality. Theses two ILIRs are no different; and to that end have been developing ISAAC (Intelligent Systems And Autonomous Controls), an Unmanned Ground Vehicle specifically designed for dismounted following.

ISAAC was designed using the $4 \mathrm{D} / \mathrm{RCS}$ reference architecture. Use of this framework enabled the merging of multiple processors and systems with varying data rates as well as giving a good starting point for vehicle design.

The vehicle is also being implemented with OE 3.0 and messaging in compliance with the AS-4/JAUS Standard. By capitalizing on the work of other agencies and development teams the designers hope to reduce the risk inherent with custom platform development as well as speed up the time it takes to field a working unit. By using a communications standard, the vehicle will have inherent interoperability with other autonomous systems. This will allow future experimentation with other autonomous solution developers.

All this allows for the vehicle to be developed with a current focus on dismounted following using vision-

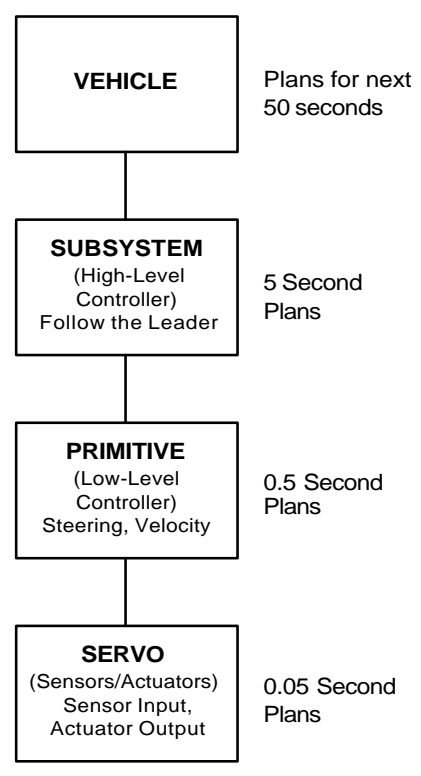

"UNCLASSIFIED" 
based techniques without pigeonholing the final product so that it cannot be expanded upon and used for future research efforts.

Vehicle

ISAAC was designed to test advancements in dismounted leader-follower technologies. To do this it would need to go where a soldier can go and move like a soldier would move - and do all this on a limited budget. To this end, the vehicle itself is based on two Bombardier ATVs spliced together; giving it dual-Ackerman steering and a readymade suspension. By going this route, a majority of the

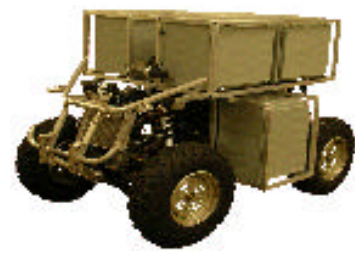
vehicle testing was eliminated and the designers need only to focus on the new subset of dynamics created with the merger. The robotic and vehicular controls are housed in multiple NEMA electrical enclosures mounted strategically on the robot's chassis. The original vehicle power system was left intact and an additional 3000 Watt generator was integrated into the system to supply the controls package.

Subsystem

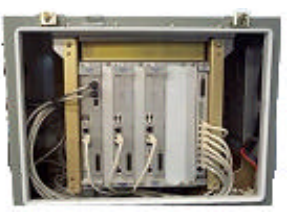

The High-Level Controller is a ruggedized rack system consisting of three $1.8 \mathrm{GHz}$ Pentium-M class processors with 1GB of DDR RAM, 60Gig Hard Drives, and 10/100 Ethernet connections. It has a 16 port 10/100 Switch, three IEEE 1394 (Firewire) ports, and a dedicated power supply. Two of the processors run Win2k Professional, while the third runs Linux.

The first two processors deal with the interface to the Low-Level Controller and Path Planning, while the Linux box is dedicated to vision processing. This is more than enough processing power to keep the update refresh rate under 5 seconds.

Primitive

The Low-Level Controller is a conglomeration of multiple dedicated processors tied together by an industrial PLC. This allows for the segmenting of the various tasks (steering, braking. transmission, throttle, and choke) while continuously monitoring for safety and control. Steering is done using a SmartMotor package that consists of a DC rotary motor, amplified, and controller in one complete package. The brake-by-wire system was developed by Delphi and is a modified version of one of their commercially available products. The transmission is controlled by a field-effect linear actuator system. This not only gives precise control, which is necessary when gears stick, but also allows for the manual shifting required during catastrophic failure. The throttle and choke are controlled by the same system using high-torque programmable digital quarter scale servos. The PLC, that links this altogether, is a 57series Premium processor from Telemecanique. It has supports multiple styles of programming, has nearly unlimited Input/Output capability (due to a distributed IO network), and supports multiple communication networks including; CAN, RS232, RS485, and 802.11g. All of these fall under the $500 \mathrm{~ms}$ requirement for this level.

Servo

"UNCLASSIFIED" 
Aside from the fundamental IO components (limit switched, pressure switches, etc...) required for vehicle operation the only sensors currently installed on the vehicle are the Stereo Pair used for pedestrian following. The pedestrian following system uses 2 MicroPix C640 cameras to capture stereo imagery. They have a 24-bit RGB color output and can capture 30 frames per second at $640 \times 480$. The cameras can be replaced by several other types of IIDC firewire cameras with similar output. These cameras are placed at least two feet apart and aligned so that each cameras horizontal field of view is on the same plan with the other.

\section{Pedestrian Following}

Following a pedestrian will be based off of a sequence of images. Initialization at the start of the system requires a user to select the pedestrian that the robotic vehicle should follow. After this, the image of the pedestrian is used as the initial template matching of the next image. The image template of the pedestrian is processed using color blob analysis and disparity. Dynamic template matching is used to combat the changes in the followed person's image. This is accomplished by replacing the last template with the new found isolated person. Changes in intensity are combated by isolating the area around the last location of the person in the new image and normalizing it. This makes the last image template the same intensity as the new image.

The tracking and following of the system will be based off of a 3-D world coordinate system. The reason for this is so the pedestrian following system can be placed on any robotic system, with minor modifications, that uses GPS following. The only major discrepancy is that this system will consider the current location as $0,0,0$ and the new calculated position, where the followed person current is $\mathrm{x}, \mathrm{y}, \mathrm{z}$. Updates will take place every second or so with a buffer so the robotic vehicle does not run into the person.

\section{State-of-the-bot}

So where along are we in this endeavor? Mechanically, the vehicle is about $90 \%$ complete. It is currently getting final modifications applied. These would be the mounting of the $3 \mathrm{~kW}$ generator, the steering encoders, and front and rear bumpers. We still need to mount the vision system and we'll need to calibrate the brake-by-wire system and bleed the lines.

Electrically, the vehicle is not as far along. The high-level controller is in the final stages of testing. We recently worked out a problem of random resets when all four boards (3 $\mathrm{CPU}+$ Ethernet cards) are running at the same time. The problem was with the power supply. After talking to the board vendor, it was discovered that the boards would reset if power dropped below 4.8 VDC level. We didn't have a supply that had sense lines to allow for feedback to the supply to keep the voltage level at the back plane to $5 \mathrm{~V}$. The only way around this was to adjust the voltage to a level to not drop below 4.9 volts at the back plane. This approach appears to have mitigated the problem. If this issue becomes a problem in the future, we will have to acquire a power supply with sense feedback capabilities. Currently, all of the low-level controllers are running together on a test-rack in our lab. When the vehicle gets back from the final mechanical modifications, we'll 
begin the process of transferring equipment from the test-rack to the vehicle's control cabinets.

The pedestrian detection and tracking system is in the beginning stages. The design of the system is complete and the algorithms are starting to be debugged in Matlab. Test images are taken, but a more thorough set of images need to be taken. The design of the code is underway. The preliminary testing of the system should take place in June with a more completed system testing on ISAAC in August.

The way ahead

So where are we going with this project? We are currently working towards an initial demo in mid to late May of 2005. This will be a sub-system level test where we prove out the individual technologies and verify they all communicate together. The goal is to tele-op the research platform.

Later in the year around early August, we plan to demo our initial following capability. Two modes of operation are being investigated. The first is direct following, where the vehicle tracks directly toward the leader. This is the simplest form of vision-based following and is therefore a great starting point. It is this mode we have targeted for the August demo.

After we've established Direct Following, we'll develop Exact Following. This is a mode of operation where the vehicle follows the exact path the leader takes. The vehicle will track the leader wherever they move in the field of view and than follow this path. This will allow the vehicle to take advantage of the leaders pathing decisions and allow it to overcome/avoid obstacles in the same manor as the leader. This gives the vehicle a better mobility capability without requiring advanced obstacle detection. We have yet to set a milestone for this demo.

\section{Looking to the Future}

ISAAC and our vision-based following research won't come to an end with the completion of our August demo. We're speculating that it will take a minimum of six to eight months to refine the Exact Following mode and after that we've already got plans for the next phases of our research.

One of the logical extensions of vision-based following is gesture-based control. Controlling an unmanned ground vehicle by using simple gestures would add yet another venue to the user interface community. By developing a system that uses the standard military ground guide commands any soldier could direct any such equipped UGV in the depot without the need of a specific soldier machine interface.

Another field of interest is integrating the work being developed by our Hands-Free TeleOperation via Physiological Signal Recognition SBIR. This involves using a microphone in the ear canal (similar to a hearing aid) to detect sub-vocal and tongue-position

"UNCLASSIFIED” 
commands. The current system looks like it will be easily adapted to our PDA user interface and could make for some really exciting experimentation.

On top of all this a few other groups have expressed interest in using the ISAAC platform to test their research efforts. This highlights one of the biggest advantages we see in having our in-house developed research platform - we built it so we know exactly how it works. We can add and remove anything we so desire without worrying about proprietary technology getting in our way.

\section{Who Else Can Benefit from This?}

Although our current applications are inline with the FCS vision of the MULE and dismounted following, the technology itself is not limited to military robotics. Any scenario where you need to carry a heavy load could be so enhanced. Consider a golf caddy that follows you from hole to hole, or a blacktop/gravel hauler for city street repair keeping step with its work force. These are just a few of the many examples that could come to mind.

$\begin{array}{ll}\text { ATD } & \text { Advanced Technology Demonstrator } \\ \text { ATV } & \text { All Terrain Vehicle } \\ \text { CAN } & \text { Component Area Network } \\ \text { CMU } & \text { Carnegie Mellon University } \\ \text { COTS } & \text { Commercial Off The Shelf } \\ \text { CPU } & \text { Central Processing Unit } \\ \text { DDR } & \text { Double Data Rate [RAM] } \\ \text { DGPS } & \text { Differential GPS } \\ \text { FCS } & \text { Future Combat System } \\ \text { GPS } & \text { Global Position System } \\ \text { IEEE } & \text { Institute for Electronic \& Electrical Engineers } \\ \text { ILIR } & \text { In-house Laboratory Independent Research } \\ \text { ISAAC } & \text { Intelligent Systems And Autonomous Controls } \\ \text { JAUS } & \text { Joint Architecture for Unmanned Systems } \\ \text { MULE } & \text { Multifunction Utility/Logistics Equipment Vehicle } \\ \text { NEMA } & \text { National Electrical Manufacturer's Association } \\ \text { OE } & \text { Operating Environment } \\ \text { OFW } & \text { Objective Force Warrior } \\ \text { ORD } & \text { Operational Requirements Document } \\ \text { PLC } & \text { Programmable Logic Controller } \\ \text { RDECOM } & \text { Research, Development, and Engineering Command } \\ \text { SBIR } & \text { Small Business Innovation Research } \\ \text { SUGV } & \text { Soldier (or Small) Unmanned Ground Vehicle } \\ \text { TARDEC } & \text { Tank-automotive and Armaments Research Development and Engineering Center } \\ \text { UGV } & \text { Unmanned Ground Vehicle }\end{array}$

1.) Global Security Organization: http://www.globalsecurity.org/military/systems/ground/fcs.htm

2.) Performance Specification for MULE, ORD for FCS

3.) Christian Science Monitor: http://csmonitor.com/2005/0127/p14s02-stct.htm

"UNCLASSIFIED" 